Original Research

\title{
Association of Club Sports Participation and TV in the Bedroom with Dietary Pattern in Austrian Adolescents
}

\author{
Clemens Drenowatz ${ }^{1,}{ }^{*}$, Gerson Ferrari ${ }^{2,3}$, Gerhard Ruedl ${ }^{4}$, Armando Cocca ${ }^{4}$, Klaus Greier ${ }^{4,5}$
}

1. Division of Sport, Physical Activity and Health, University of Education Upper Austria, Linz, Austria; E-Mail: clemens.drenowatz@ph-ooe.at

2. Escuela de Ciencias de la Actividad Física, el Deporte y la Salud, Universidad de Santiago de Chile (USACH), Santiago, Chile; E-Mail: gerson.demoraes@usach.cl

3. Human Performance Lab, Education, Physical Activity and Health Research Unit (GEEAFyS), Universidad Católica el Maule, Talca, Chile

4. Department of Sport Science, University of Innsbruck, Innsbruck, Austria; E-Mails: gerhard.ruedl@uibk.ac.at; armando.cocca@uibk.ac.at; nikolaus.greier@kph-es.at

5. Divison of Physical Education, Private Educational College (KPH-ES), Stams, Austria

* Correspondence: Clemens Drenowatz; E-Mail: Clemens.drenowatz@ph-ooe.at

Academic Editor: Jennifer Keogh

Recent Progress in Nutrition

2022, volume 2 , issue 1

doi:10.21926/rpn.2201004
Received: November 15, 2021

Accepted: February 14, 2022

Published: February 18, 2022

\begin{abstract}
Poor lifestyle choices in adolescents, including low physical activity (PA), excess screen time, and unhealthy dietary habits, are major threats to their health in the future. Unhealthy behaviors such as insufficient PA, high TV time, and poor dietary choices also tend to cluster, but information on the combined association of screen time, sports participation, and dietary habits is limited in Austrian youth. To examine the association among these behaviors, 165 adolescents ( 74 girls and 91 boys) between 11 and 14 years of age completed a food frequency questionnaire during regular class hours. Additionally, participants reported whether they participated in club sports and whether they had a TV in the bedroom. The results showed that there were no interaction effects of club sports participation and TV in the bedroom on dietary habits. There were also no significant associations between participation in club sports and dietary habits. Having a TV in the bedroom, however, was associated with more frequent
\end{abstract}

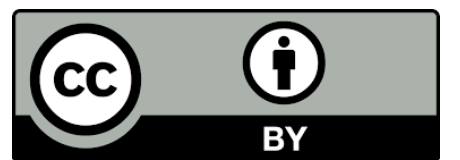

(C) 2022 by the author. This is an open access article distributed under the conditions of the Creative Commons by Attribution License, which permits unrestricted use, distribution, and reproduction in any medium or format, provided the original work is correctly cited. 
consumption of fast food and soft drinks. These results highlight the detrimental effects of unsupervised access to a TV on dietary habits in youth. As many lifestyle habits are established during adolescence and retained in adulthood, this age is important to develop a healthy lifestyle. Although club sports provide a viable setting to promote health, the results of this study indicate that the potential of club sports to educate children on nutrition is underused.

\section{Keywords}

Sports; physical activity; media consumption; screen time; diet; food intake; youth

\section{Introduction}

Low physical activity (PA) levels, along with high screen time and poor nutrition, are major health risk factors [1-3]. More than $80 \%$ of young individuals do not meet the current PA recommendations $[4,5]$. Additionally, screen time among adolescents has increased significantly over the last decades [6], and this age group also consumes fast food and soft drinks the most [7]. As many lifestylerelated behaviors are established during adolescence and retained in adulthood [8], these behaviors can significantly affect the health of these individuals in the future. Resnick et al. argued that $70 \%$ of premature deaths can be attributed to behavioral choices that start during adolescence [9], and poor dietary habits at a young age have been associated with an increase in the risk of cardiovascular and metabolic diseases in later life $[10,11]$. Furthermore, eating behaviors have been associated with academic performance, cognitive function, and psychological well-being [12, 13]. An increase in the nutritional requirements due to growth and maturation also make adolescence a vulnerable period for inadequate dietary intake [14]. Frequently eating away from home might increase the risk of poor dietary choices [15]. and snacks provide a considerable amount of the total daily energy intake, particularly in adolescents [16]. High snack consumption is also commonly associated with the consumption of highly processed and energy-dense foods, as they are often selected based on taste rather than nutrition [16]. Given the implications for current and future health, it is important to examine key correlates of dietary habits in adolescents.

Behavioral choices are largely influenced by environmental influences, such as access to sports facilities and electronic media, as well as, food availability [17-19]. With club sports participation rates among youth between $40 \%$ and $59 \%$ across the globe $[4,20]$ and approximately $66 \%$ in Europe [21], club sports are considered a viable setting to promote health due to their association with various health benefits in children and adolescents [22]. Besides increasing PA during adolescence $[21,23,24]$, participation in club sports among youth is associated with higher PA in adulthood [25, 26]. Further, positive associations between club sports participation and socio-emotional outcomes were found [27, 28]. Additionally, some studies have shown a beneficial association between club sports participation and dietary choices [29-31], while others have reported no difference or even a greater likelihood of fast food and soft drink consumption with club sports participation among youth $[24,32,33]$.

Although studies on the association between club sports participation and dietary habits have provided equivocal results, screen time in general, and TV time in particular, has been consistently associated with unhealthy dietary habits that include a higher intake of fast food and soft drinks, as 
well as, lower consumption of fruits and vegetables [34-37]. The detrimental effects of TV time on dietary intake have partially been attributed to food advertisements specifically targeting youth [38, 39], rather than the inhibition of PA $[40,41]$. Low attention while eating due to watching TV might also contribute to a disruption of satiety cues and impaired memory of foods consumed, which can increase the risk of overconsumption [42]. Studies on the combined effect of PA and the presence or absence of a TV in the bedroom on the dietary habits of youth are limited. In this study, we examined the independent and combined effects of sports participation and having a TV in the bedroom on dietary choices in Austrian adolescents.

\section{Materials and Methods}

Nine classes from grades six to eight were selected from Austrian middle schools, with 172 eligible participants who were 11 - to 14 years old. Parents received information about the nature of the study and provided written informed consent; the participants provided oral assent at the time of data collection, which occurred in May and June of 2018. The study protocol was approved by the Institutional Review Board of the University of Innsbruck (approval number: 16/2017) and the school board of the Federal State of Tyrol, Austria. All study procedures followed the ethical standards of the 2008 Declaration of Helsinki.

Body weight $(\mathrm{kg})$ and height $(\mathrm{cm})$ of the participants were measured by trained technicians according to standard procedures during a physical education class, where the participants were barefoot and wearing gym clothes. Specifically, body weight was measured to the nearest $0.1 \mathrm{~kg}$ using a gauged body scale (SECA ${ }^{\circledR} 803$, Seca, Hamburg, Germany) and height was measured to the nearest $0.1 \mathrm{~cm}$ using a mobile stadiometer (SECA ${ }^{\circledR} 217$, Seca, Hamburg, Germany). Subsequently, body mass index (BMI, $\mathrm{kg} / \mathrm{m}^{2}$ ) was calculated and converted to BMI percentiles (BMIPCT) based on the German reference system [43]. Participants with a BMIPCT above the $90^{\text {th }}$ percentile were considered to be overweight/obese.

Dietary information was obtained via a standardized food frequency questionnaire that was used previously in Austrian adolescents [44]. The questionnaire was administered during regular class hours by trained personnel and participants were asked to report the frequency (days/week) of the consumption of 42 food items. The responses were subsequently summarized into 12 food groups. Then, a principal component analysis was performed, and three factors were identified with an Eigenvalue $>1$ that explained $55.9 \%$ of the total variance of dietary intake. Specifically, factor 1 was characterized by high loadings for the consumption of meat, fish, bread (white and/or wholemeal), pasta, and sweets (meat/CHO); factor 2 was characterized by high loadings for the consumption of milk, cereal, nuts, and fruits (milk/cereal); factor 3 was characterized by high loadings for the consumption of water and vegetables, as well as, low consumption of fast food and soft drinks (water/vegetable).

Additionally, participants reported whether they had a TV in their bedroom (yes or no) and participated in club sports (yes or no) along with the time spent in club sports and watching TV. Due to the limited variability in the time spent in club sports and a low response rate on the time spent watching TV, the participants were grouped based on club sports participation (club sports vs. no club sports) and having a TV in the bedroom (TV in room vs. no TV in room).

Statistical analysis. Descriptive statistics were reported as the mean \pm standard deviation for continuous variables and prevalence for categorical variables. The normality of the data was 
checked by visual inspection of the q-q plots. Sex differences in anthropometric characteristics and dietary pattern were examined by performing ANOVA, and $2 \times 2$ ANOVA was performed to examine the differences in the dietary pattern by participation in club sports and TV in the bedroom. $A$ subsequent $2 \times 2$ ANCOVA was performed with sex as a covariate due to the observed differences in dietary pattern between boys and girls. All statistical analyses were conducted in SPSS 27.0 (IBM, Armonk, NY) with statistical significance set at $p<0.05$.

\section{Results}

Complete data were obtained from 165 participants ( 74 girls and 91 boys). The participants were $12.9 \pm 1.2$ years old, and the prevalence of overweight/obesity was $18.8 \%$. Of the total sample, $48.5 \%$ reported club sports participation and having a TV in the bedroom. There were no sex differences in the prevalence of overweight/obesity and club sports participation. Boys, however, were more likely to have a TV in their bedroom than girls ( $58.2 \%$ vs. $36.5 \%, p<0.01)$.

Boys were also significantly older than girls $(p<0.01)$. Thus, there was a significant sex difference in body weight and height, while BMIPCT was similar in boys and girls (Table 1). Boys reported more frequent consumption of meat and soft drinks $(p<0.01)$, while girls reported more frequent consumption of fruits and vegetables $(p<0.05)$. These differences also resulted in higher scores for the meat/CHO factor $(p=0.02)$ and lower scores for the water/vegetable factor $(p<0.01)$ in boys than in girls.

Table 1 Anthropometric characteristics and food intake (mean \pm SD) for all participants and independently for boys and girls.

\begin{tabular}{cccc}
\hline & $\begin{array}{c}\text { Total Sample } \\
(\mathrm{N}=165)\end{array}$ & $\begin{array}{c}\text { Girls } \\
(\mathrm{N}=74)\end{array}$ & $\begin{array}{c}\text { Boys } \\
(\mathrm{N}=91)\end{array}$ \\
\hline Age (years) $* *$ & $12.9 \pm 1.2$ & $12.7 \pm 1.1$ & $13.1 \pm 1.2$ \\
Height (cm) ** & $161.3 \pm 8.9$ & $158.8 \pm 6.8$ & $163.4 \pm 9.9$ \\
Body weight (kg) ${ }^{*}$ & $53.8 \pm 14.3$ & $51.3 \pm 9.9$ & $55.9 \pm 16.9$ \\
BMI Percentile & $59.4 \pm 29.4$ & $60.9 \pm 27.5$ & $58.2 \pm 31.0$ \\
& & & \\
Fruits (days/week) ${ }^{*}$ & $2.7 \pm 1.2$ & $2.9 \pm 1.3$ & $2.6 \pm 1.1$ \\
Vegetables (days/week) $* *$ & $2.5 \pm 1.5$ & $2.9 \pm 1.6$ & $2.2+1.4$ \\
Nuts \& Seeds (days/week) & $1.2 \pm 0.9$ & $1.2 \pm 1.0$ & $1.2+0.9$ \\
Pasta \& Rice (days/week) & $2.2 \pm 1.1$ & $2.2 \pm 1.0$ & $2.2 \pm 1.1$ \\
Bread (days/week) & $3.2 \pm 0.8$ & $3.3 \pm 0.8$ & $3.1 \pm 1.0$ \\
Meat (days/week) ** & $2.5 \pm 1.2$ & $2.1 \pm 1.1$ & $2.7+1.2$ \\
Fish \& Egg (days/week) & $1.8 \pm 1.2$ & $1.6 \pm 1.0$ & $2.0 \pm 1.3$ \\
Fast Food (days/week) & $1.6 \pm 0.9$ & $1.5 \pm 0.8$ & $1.7 \pm 0.9$ \\
Sweets (days/week) & $2.6 \pm 1.1$ & $2.5 \pm 1.1$ & $2.7 \pm 1.2$ \\
Soft drink (days/week) ** & $2.3 \pm 1.3$ & $2.0 \pm 1.1$ & $2.6 \pm 1.3$ \\
Water (days/week) & $4.4 \pm 1.6$ & $4.6 \pm 1.7$ & $4.2 \pm 1.5$ \\
Milk (days/week) & $2.2 \pm 1.0$ & $2.2 \pm 1.1$ & $2.3 \pm 1.0$ \\
\hline
\end{tabular}

BMI... body mass index; Sex differences: ${ }^{*} p<0.05,{ }^{* *} p<0.01$ 
There were no significant TV in the bedroom by club sports interaction effects on dietary pattern (Table 2). Dietary pattern also did not differ by club sports participation but differed significantly with having a TV in the bedroom. Participants with a TV in their bedroom reported more frequent consumption of fast food and soft drinks than participants without a TV in their bedroom (1.8 \pm 0.9 vs. $1.4 \pm 0.8$ and $2.6 \pm 1.3$ vs. $2.1 \pm 1.2$ days/week, respectively; $p<0.05$ ) along with a borderline significant difference in the frequency of meat consumption $(2.6 \pm 1.2$ vs. $2.3 \pm 1.1$ days/week; $p=0.06$ ) (Table 2). After adjusting for sex, the difference in fast food consumption remained significant $(p<0.01)$, while soft drink consumption was similar between the participants with and without a TV in their bedroom.

Table 2 Frequency (days/week) of the consumption of food groups by club sports participation and having a TV in the bedroom (mean \pm SD).

\begin{tabular}{lllll}
\hline & \multicolumn{2}{l}{ TV/Computer in Room } & \multicolumn{2}{l}{ TV/Computer not in Room } \\
& Club Sports & No Club Sports & Club Sports & No Club Sports \\
\hline Fruits & $2.9 \pm 1.3$ & $2.5 \pm 1.0$ & $2.9 \pm 1.2$ & $2.7 \pm 1.2$ \\
Vegetables & $2.3 \pm 1.4$ & $2.3 \pm 1.6$ & $2.8 \pm 1.6$ & $2.6 \pm 1.5$ \\
Nuts \& Seeds & $1.3 \pm 1.0$ & $1.1 \pm 1.0$ & $1.2 \pm 1.0$ & $1.2 \pm 0.8$ \\
Pasta \& Rice & $2.3 \pm 0.8$ & $2.4 \pm 1.2$ & $2.0 \pm 1.0$ & $2.3 \pm 1.1$ \\
Bread & $3.2 \pm 0.9$ & $3.1 \pm 0.9$ & $3.1 \pm 0.9$ & $3.3 \pm 0.9$ \\
Meat & $2.6 \pm 1.2$ & $2.6 \pm 1.2$ & $2.1 \pm 1.2$ & $2.4 \pm 1.1$ \\
Fish \& Egg & $1.8 \pm 1.2$ & $2.0 \pm 1.4$ & $1.6+0.9$ & $1.7 \pm 1.0$ \\
Fast Food ${ }^{*}$ & $1.7 \pm 0.8$ & $1.9 \pm 1.0$ & $1.3 \pm 0.7$ & $1.5 \pm 0.9$ \\
Sweets & $2.7 \pm 1.2$ & $2.7 \pm 1.2$ & $2.4 \pm 1.0$ & $2.6 \pm 1.1$ \\
Soft drink * & $2.5 \pm 1.3$ & $2.6 \pm 1.3$ & $2.1 \pm 1.1$ & $2.2 \pm 1.4$ \\
Water & $4.6 \pm 1.9$ & $4.3 \pm 1.7$ & $4.2 \pm 1.3$ & 4.31 .4 \\
Milk & $2.4 \pm 0.9$ & $2.0 \pm 1.0$ & $2.2 \pm 1.0$ & $2.3 \pm 1.1$ \\
\hline
\end{tabular}

* sig. main effect for TV in bedroom $(p<0.05)$

Having a TV in the bedroom was also associated with higher scores for the meat/CHO factor $(p=0.01)$. Additionally, there was a borderline significant difference in the meat/CHO factor scores associated with club sports participation $(p=0.06)$ with lower scores for club sports participants compared to the score of their peers who did not participate in club sports (Figure 1). Other dietary factors did not differ with TV in the bedroom or club sports participation. These results were similar after adjusting for sex. 


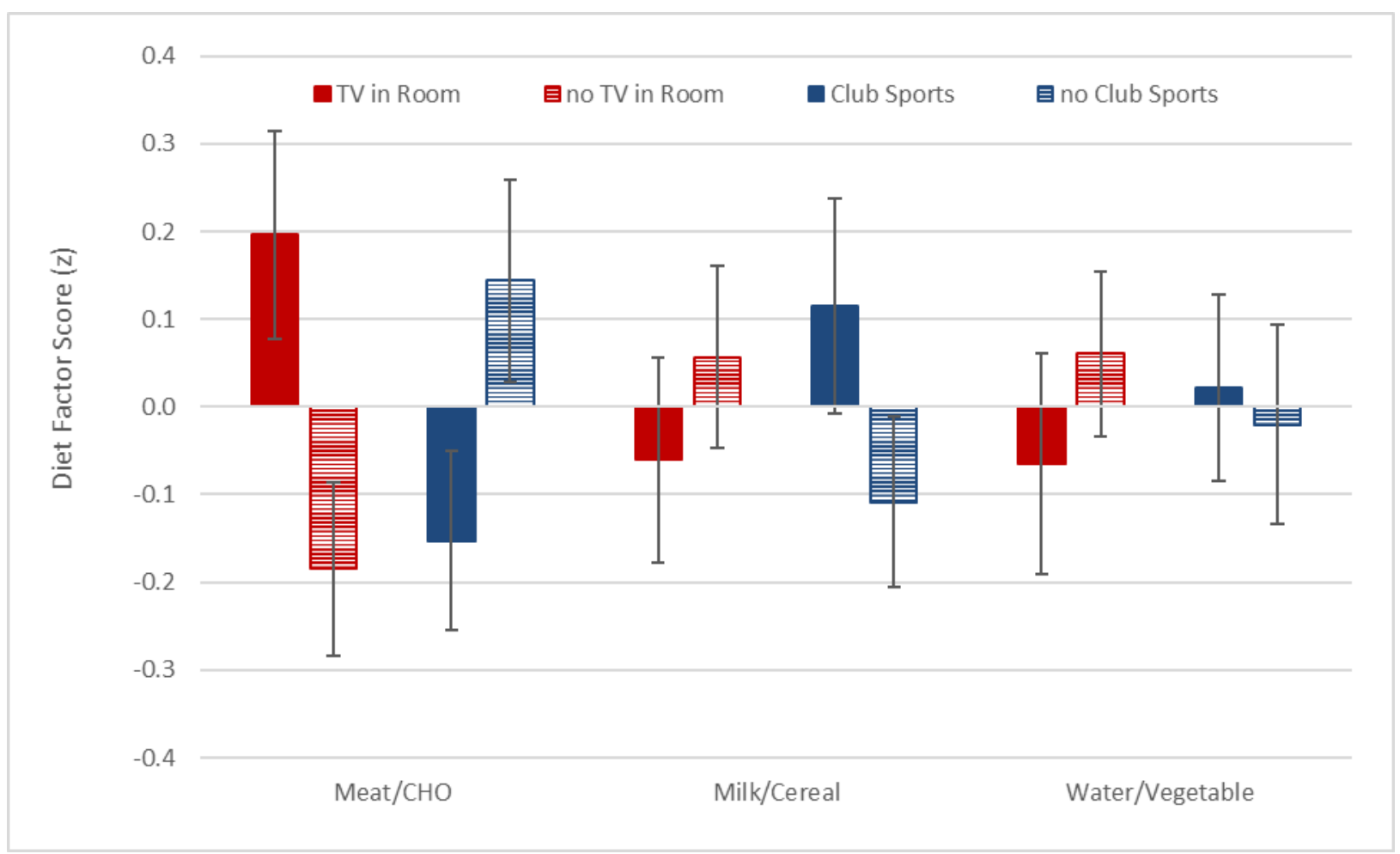

Figure 1 The diet scores (mean $\pm \mathrm{SE}$ ) for the presence/absence of TV in the bedroom and participation/no participation in club sports.

\section{Discussion}

In this study, we examined the combined effects of club sports participation and having a TV in the bedroom on dietary habits in Austrian adolescents. There were no significant interaction effects of club sports participation and TV time on dietary habits. Having a TV in the bedroom, however, was significantly associated with diet, while the association between diet and club sports participation was not significant. Specifically, having a TV in the bedroom was associated with a more frequent consumption of unhealthy food items, such as fast food and soft drinks. Additionally, boys consumed meat and soft drinks more frequently than girls, while girls consumed fruits and vegetables more frequently than boys.

Other studies have also shown that girls consume fruits and vegetables more frequently than boys [29, 30,45] andthe limited association between sports participation and dietary intake has been reported previously as well [45]. Heikkilä et al., therefore, argued that dietary habits are more strongly associated with vigorous PA rather than participation in club sports [45]. However, club sports can promote health among youth [46], and some studies have shown beneficial associations between dietary intake and participation in club sports. Torstveit et al., for example, reported healthier food choices, including lower consumption of soft drinks, salty snacks, and candy, as well as a higher intake of fruits and vegetables in club sports participants who were 13 to 17 years old [29]. Additionally, club sports participation was associated with more regular meal intake and a higher frequency of eating breakfast and lunch. To influence the dietary choices in adolescents, it might, however, be necessary to address the importance of nutrition for improving the performance and general development in the club sport setting, but, research on nutrition education in club sports remains limited [45]. The inconsistencies regarding the association between participation in 
club sports and dietary habits in adolescents further indicated that PA and dietary habits are complex behaviors that are influenced by various factors, including access to and time spent watching TV.

Several studies have shown that sedentary behavior and poor dietary habits cluster together [47] with larger detrimental effects of screen-based activities on dietary habits than the total sitting time, which includes reading or academic work in addition to the use of electronic media [48]. Particularly, high TV time has been associated with dietary habits in children and adolescents [34, 35, 37] and caused a lower intake of protein, minerals, vitamins, and dietary fiber [49]. Even though we did not directly assess the amount of time spent watching TV, previous studies showed a direct association between having a TV in the bedroom and TV time [50, 51]. In fact, Adachi-Mejia et al. reported a stronger association between excess body weight and the presence of a TV in the bedroom compared to the association between TV time and excess body weight [51]. Having a TV in the bedroom was also associated with fewer family meals [50], which might contribute to poorer dietary habits [52]. Lack of family meals might also contribute to a more irregular eating pattern and more frequent consumption of snacks, which are generally of low nutritional quality [48]. As eating while watching TV is a common habit among adolescents $[16,53]$, it might also increase the risk of unhealthy dietary habits later in life because dietary habits are carried over from youth into adulthood [54].

The detrimental effects of screen time in general, and watching TV in particular, have been attributed to food advertisements and potential conditioning to eat while watching TV, as well as, distraction and disruption of food memory along with the interruption of physiological food regulation [42]. Food advertising not only influences food consumption but also affects food preference that can lead to a greater consumption of sweet and high-fat savory foods while decreasing the intake of fruits and vegetables $[55,56]$. Dietary intake also increases during screenbased activities, even in the absence of food advertisements [57, 58]. Particularly, soft drink consumption was higher when watching TV compared to eating while listening to music or eating in a group [59]. The distraction caused by watching TV might lead to a lack of attention to the quality and quantity of food consumed [42]. Furthermore, the ability to accurately estimate food intake might be impaired while watching TV [60]. This not only affects the current energy intake but also the food intake during subsequent meals $[42,61]$. Higher TV time is also associated with a greater chance of skipping breakfast [62], which has detrimental effects on diet quality and health in youth [63]. Consuming unhealthy food while watching TV at a young age leads to the development of a specific habit, and watching TV potentially becomes an automatic cue for certain food choices [64]. Accordingly, a longitudinal study with more than 900 adolescents showed a direct association between the change in TV time and the consumption of soft drinks and snacks, independent of PA [41]. Since screen time is a relatively stable behavior that is carried over from childhood into adolescence and adulthood [65], excess screen time should be monitored early in life.

Some limitations of this study, however, need to be considered when interpreting the results. Convenience sampling was performed, and a relatively small number of participants were studied, which might limit the generalizability of the results. Moreover, causal relationships cannot be established due to the cross-sectional nature of this study. As the information on diet, sports participation, and having a TV in the bedroom was obtained via self-report, there is a risk of bias due to social desirability and social approval. Additionally, participants reported the frequency rather than the total amount of foods consumed, and missing foods on the food frequency 
questionnaire could affect the reported dietary intake. These problems, however, are common in dietary assessments in epidemiological studies, and the administration of the questionnaire under supervision along with the assessment of diverse food items that are commonly consumed by Austrian youth increased the strength of the study.

\section{Conclusions}

Similar to previous studies, this study highlighted the detrimental health effects of unsupervised access to a TV due to the increased risk of high TV time and its association with poor dietary choices. The lack of interaction effects further showed that PA and media consumption need to be considered as independent constructs. Although club sports provide opportunities for healthenhancing behaviors that could compensate for sedentary periods, the full potential of club sports for health education is currently underutilized. Studies have shown that health promotion is not prioritized by club sports in youth [66]. Adolescence, however, is a crucial period to develop various lifestyle habits [54], including PA and dietary habits, that are retained in adulthood. Health promotion in multiple settings, including sports clubs, schools, and family groups, that address the effects of excess media consumption on PA and dietary habits, therefore, is necessary to improve the health of the population in the long term.

\section{Author Contributions}

Conceptualization, K.G. and C.D.; methodology, K.G.; formal analysis, C.D.; writing-original draft preparation, C.D.; writing-review and editing, G.F., G.R., A.C. and K.G.; All authors have read and agreed to the published version of the manuscript.

\section{Competing Interests}

The authors have declared that no competing interests exist.

\section{References}

1. Carson V, Hunter S, Kuzik N, Gray CE, Poitras VJ, Chaput JP, et al. Systematic review of sedentary behaviour and health indicators in school-aged children and youth: An update. Appl Physiol Nutr Metab. 2016; 41: S240-S265.

2. Poitras VJ, Gray CE, Borghese MM, Carson V, Chaput JP, Janssen I, et al. Systematic review of the relationships between objectively measured physical activity and health indicators in school-aged children and youth. Appl Physiol Nutr Metab. 2016; 41: S197-S239.

3. Funtikova AN, Navarro E, Bawaked RA, Fíto M, Schröder H. Impact of diet on cardiometabolic health in children and adolescents. Nutr J. 2015; 14: 1-11.

4. Hallal PC, Andersen LB, Bull FC, Guthold R, Haskell W, Ekelund U, et al. Global physical activity levels: Surveillance progress, pitfalls, and prospects. Lancet. 2012; 380: 247-257.

5. Sallis JF, Bull F, Guthold R, Heath GW, Inoue S, Kelly P, et al. Progress in physical activity over the Olympic quadrennium. Lancet. 2016; 388: 1325-1336.

6. Bucksch J, Sigmundova D, Hamrik Z, Troped PJ, Melkevik O, Ahluwalia N, et al. International trends in adolescent screen-time behaviors from 2002 to 2010. J Adolesc Health. 2016; 58: 417425. 
7. Börnhorst $C$, Wijnhoven TM, Kunešová M, Yngve A, Rito Al, Lissner L, et al. WHO European childhood obesity surveillance Initiative: Associations between sleep duration, screen time and food consumption frequencies. BMC Public Health. 2015; 15: 1-11.

8. Sawyer SM, Afifi RA, Bearinger LH, Blakemore SJ, Dick B, Ezeh AC, et al. Adolescence: A foundation for future health. Lancet. 2012; 379: 1630-1640.

9. Resnick MD, Catalano RF, Sawyer SM, Viner R, Patton GC. Seizing the opportunities of adolescent health. Lancet. 2012; 379: 1564-1567.

10. Kaikkonen JE, Mikkilä V, Magnussen CG, Juonala M, Viikari JS, Raitakari OT. Does childhood nutrition influence adult cardiovascular disease risk?--insights from the Young Finns Study. Ann Med. 2013; 45: 120-128.

11. Wennberg M, Gustafsson PE, Wennberg P, Hammarström A. Poor breakfast habits in adolescence predict the metabolic syndrome in adulthood. Public Health Nutr. 2015; 18: 122129.

12. Cooper SB, Bandelow S, Nevill ME. Breakfast consumption and cognitive function in adolescent schoolchildren. Physiol Behav. 2011; 103: 431-439.

13. Sánchez-Villegas A, Toledo E, de Irala J, Ruiz-Canela M, Pla-Vidal J, Martínez-González MA. Fastfood and commercial baked goods consumption and the risk of depression. Public Health Nutr. 2012; 15: 424-432.

14. Moreno LA, Rodriguez G, Fleta J, Bueno-Lozano M, Lazaro A, Bueno G. Trends of dietary habits in adolescents. Crit Rev Food Sci Nutr. 2010; 50: 106-112.

15. Piernas C, Popkin BM. Food portion patterns and trends among U.S. children and the relationship to total eating occasion size, 1977-2006. J Nutr. 2011; 141: 1159-1164.

16. Larson NI, Miller JM, Watts AW, Story MT, Neumark-Sztainer DR. Adolescent snacking behaviors are associated with dietary intake and weight status. J Nutr. 2016; 146: 1348-1355.

17. Popkin BM, Duffey K, Gordon-Larsen P. Environmental influences on food choice, physical activity and energy balance. Physiol Behav. 2005; 86: 603-613.

18. Ding D, Sallis JF, Kerr J, Lee S, Rosenberg DE. Neighborhood environment and physical activity among youth a review. Am J Prev Med. 2011; 41: 442-455.

19. Barnett TA, Kelly AS, Young DR, Perry CK, Pratt CA, Edwards NM, et al. Sedentary behaviors in today's youth: Approaches to the prevention and management of childhood obesity: A scientific statement from the American Heart Association. Circulation. 2018; 138: e142-e159.

20. Tremblay MS, Barnes JD, González SA, Katzmarzyk PT, Onywera VO, Reilly JJ, et al. Global matrix 2.0: Report card grades on the physical activity of children and youth comparing 38 countries. J Phys Act Health. 2016; 13: S343-S366.

21. Kokko S, Martin L, Geidne S, Van Hoye A, Lane A, Meganck J, et al. Does sports club participation contribute to physical activity among children and adolescents? A comparison across six European countries. Scand J Public Health. 2018: 47: 851-858.

22. Geidne S, Quennerstedt M, Eriksson C. The youth sports club as a health-promoting setting: An integrative review of research. Scand J Public Health. 2013; 41: 269-283.

23. Mäkelä K, Kokko S, Kannas L, Villberg J, Vasankari T, Heinonen O, et al. Physical activity, screen time, and sleep among youth participating and non-participating in organized sports - The Finnish health promoting Sports Club (FHPSC) Study. Adv Phys Educ. 2016; 6: 378-388. 
24. Nelson TF, Stovitz SD, Thomas M, LaVoi NM, Bauer KW, Neumark-Sztainer D. Do youth sports prevent pediatric obesity? A systematic review and commentary. Curr Sports Med Rep. 2011; 10: $360-370$.

25. Azevedo $M R$, Araújo $C L$, da Silva $M C$, Hallal PC. Tracking of physical activity from adolescence to adulthood: A population-based study. Rev Saude Publica. 2007; 41: 69-75.

26. Kjønniksen L, Anderssen N, Wold B. Organized youth sport as a predictor of physical activity in adulthood. Scand J Med Sci Sports. 2009; 19: 646-654.

27. Badura P, Geckova AM, Sigmundova D, van Dijk JP, Reijneveld SA. When children play, they feel better: Organized activity participation and health in adolescents. BMC Public Health. 2015; 15: 1-8.

28. Eime RM, Young JA, Harvey JT, Charity MJ, Payne WR. A systematic review of the psychological and social benefits of participation in sport for children and adolescents: Informing development of a conceptual model of health through sport. Int J Behav Nutr Phys Act. 2013; 10: 1-21.

29. Torstveit MK, Johansen BT, Haugland SH, Stea TH. Participation in organized sports is associated with decreased likelihood of unhealthy lifestyle habits in adolescents. Scand J Med Sci Sports. 2018; 28: 2384-2396.

30. Voráčová J, Badura P, Hamrik Z, Holubčíková J, Sigmund E. Unhealthy eating habits and participation in organized leisure-time activities in Czech adolescents. Eur J Pediatr. 2018; 177: 1505-1513.

31. Dortch KS, Gay J, Springer A, Kohl HW, Sharma S, Saxton D, et al. The association between sport participation and dietary behaviors among fourth graders in the school physical activity and nutrition survey, 2009-2010. Am J Health Promot. 2014; 29: 99-106.

32. Heikkilä L, Koorpelainen R, Aira T, Alanko L, Heinonen O, Kokko S, et al. The associations between adolescents' sports club participation and dietary habits. Transl Sports Med. 2021; 4: 617-626.

33. Vella SA, Cliff DP, Okely AD, Scully ML, Morley BC. Associations between sports participation, adiposity and obesity-related health behaviors in Australian adolescents. Int J Behav Nutr Phys Act. 2013; 10: 1-9.

34. Shqair AQ, Pauli LA, Costa VP, Cenci M, Goettems ML. Screen time, dietary patterns and intake of potentially cariogenic food in children: A systematic review. J Dent. 2019; 86: 17-26.

35. Pearson N, Biddle SJ. Sedentary behavior and dietary intake in children, adolescents, and adults. A systematic review. Am J Prev Med. 2011; 41: 178-188.

36. Hobbs M, Pearson N, Foster PJ, Biddle SJ. Sedentary behaviour and diet across the lifespan: An updated systematic review. Br J Sports Med. 2015; 49: 1179-1188.

37. Avery A, Anderson C, McCullough F. Associations between children's diet quality and watching television during meal or snack consumption: A systematic review. Matern Child Nutr. 2017; 13: e12428.

38. Harris JL, Bargh JA, Brownell KD. Priming effects of television food advertising on eating behavior. Health Psychol. 2009; 28: 404-413.

39. Hitchings E, Moynihan P. The relationship between television food advertisements recaled and actual foods consumed by children. J Hum Nutr Diet. 2008; 11: 511-517. 
40. Marshall S, Biddle S, Gorely T, Cameron N, Murday E. Relationships between media use, body fatness and physical activity in children and youth: A meta-analysis. Int J Obes (Lond). 2004; 28 : 1238-1246.

41. Gebremariam MK, Bergh IH, Andersen LF, Ommundsen $\mathrm{Y}$, Totland TH, Bjelland M, et al. Are screen-based sedentary behaviors longitudinally associated with dietary behaviors and leisuretime physical activity in the transition into adolescence? Int J Behav Nutr Phys Act. 2013; 10: 18.

42. Marsh S, Ni Mhurchu C, Maddison R. The non-advertising effects of screen-based sedentary activities on acute eating behaviours in children, adolescents, and young adults. A systematic review. Appetite. 2013; 71: 259-273.

43. Kromeyer-Hauschild K, Wabitsch M, Kunze D, Geller F, Geiß H, Hesse V, et al. Perzentile für den Body-mass-Index für das Kindes- und Jugendalter unter Heranziehung verschiedener deutscher Stichproben. Monatsschrift Kinderheilkunde. 2001; 149: 807-818.

44. Greier K, Ruedl G, Weber C, Thöni G, Riechelmann H. Ernährungsverhalten und motorische Leistungsfähigkeit von 10- bis 14-jährigen Jugendlichen. Ernährung Medizin. 2016; 31: 166-171.

45. Heikkilä L, Korpelainen R, Tuula A, Alanko L, Heinonen O, Kokko S, et al. The association between adoelscents' sports club participation and dietary habits. Transl Sports Med. 2021; 4: 617-626.

46. Kokko S. Sports clubs as settings for health promotion: Fundamentals and an overview to research. Scand J Public Health. 2014; 42: 60-65.

47. Leech RM, McNaughton SA, Timperio A. The clustering of diet, physical activity and sedentary behavior in children and adolescents: A review. Int J Behav Nutr Phys Act. 2014; 11: 1-9.

48. Fletcher EA, McNaughton SA, Crawford D, Cleland V, Della Gatta J, Hatt J, et al. Associations between sedentary behaviours and dietary intakes among adolescents. Public Health Nutr. 2018; 21: 1115-1122.

49. Tsujiguchi H, Hori D, Kambayashi Y, Hamagishi T, Asakura H, Mitoma J, et al. Relationship between screen time and nutrient intake in Japanese children and adolescents: A crosssectional observational study. Environ Health Prev Med. 2018; 23: 1-12.

50. Barr-Anderson DJ, van den Berg P, Neumark-Sztainer D, Story M. Characteristics associated with older adolescents who have a television in their bedrooms. Pediatrics. 2008; 121: 718-724.

51. Adachi-Mejia AM, Longacre MR, Gibson JJ, Beach ML, Titus-Ernstoff LT, Dalton MA. Children with a TV in their bedroom at higher risk for being overweight. Int J Obes (Lond). 2007; 31: 644651.

52. Hammons AJ, Fiese BH. Is frequency of shared family meals related to the nutritional health of children and adolescents? Pediatrics. 2011; 127: e1565-e1574.

53. Oliveira JS, Barufaldi LA, Abreu GA, Leal VS, Brunken GS, Vasconcelos SM, et al. ERICA: Use of screens and consumption of meals and snacks by Brazilian adolescents. Rev Saude Publica. 2016; 50: 7s.

54. Craigie AM, Lake AA, Kelly SA, Adamson AJ, Mathers JC. Tracking of obesity-related behaviours from childhood to adulthood: A systematic review. Maturitas. 2011; 70: 266-284.

55. Blass EM, Anderson DR, Kirkorian HL, Pempek TA, Price I, Koleini MF. On the road to obesity: Television viewing increases intake of high-density foods. Physiol Behav. 2006; 88: 597-604.

56. Halford JC, Gillespie J, Brown V, Pontin EE, Dovey TM. Effect of television advertisements for foods on food consumption in children. Appetite. 2004; 42: 221-225. 
57. Chaput JP, Klingenberg L, Astrup A, Sjödin AM. Modern sedentary activities promote overconsumption of food in our current obesogenic environment. Obes Rev. 2011; 12: e12-e20.

58. Volkow ND, Wang GJ, Fowler JS, Tomasi D, Baler R. Food and drug reward: Overlapping circuits in human obesity and addiction. Curr Top Behav Neurosci. 2011; 11: 1-24.

59. Péneau S, Mekhmoukh A, Chapelot D, Dalix AM, Airinei G, Hercberg S, et al. Influence of environmental factors on food intake and choice of beverage during meals in teenagers: A laboratory study. Br J Nutr. 2009; 102: 1854-1859.

60. Moray J, Brill A, Mayoral M. Viewing television while eating impairs the abiity to accurately estimate total amount of food consumed. Bariatr Nurs Surg Patient Care. 2006; 2: 71-76.

61. Mittal D, Stevenson R, Oaten M, Miller L. Snacking while watching TV impairs food recall and promotes food intake on a later TV free test meal. Appl Cogn Psychol. 2011; 25: 871-877.

62. Tambalis KD, Panagiotakos DB, Psarra G, Sidossis LS. Screen time and its effect on dietary habits and lifestyle among schoolchildren. Cent Eur J Public Health. 2020; 28: 260-266.

63. Medin AC, Myhre JB, Diep LM, Andersen LF. Diet quality on days without breakfast or lunch Identifying targets to improve adolescents' diet. Appetite. 2019; 135: 123-130.

64. de Bruijn GJ, van den Putte B. Adolescent soft drink consumption, television viewing and habit strength. Investigating clustering effects in the Theory of Planned Behaviour. Appetite. 2009; 53: 66-75.

65. Biddle SJ, Pearson N, Ross GM, Braithwaite R. Tracking of sedentary behaviours of young people: A systematic review. Prev Med. 2010; 51: 345-351.

66. Meganck J, Scheerder J, Thibaut E, Seghers J. Youth sports clubs' potential as health-promoting setting: Profiles, motives and barriers. Health Educ J. 2015; 74: 531-543.

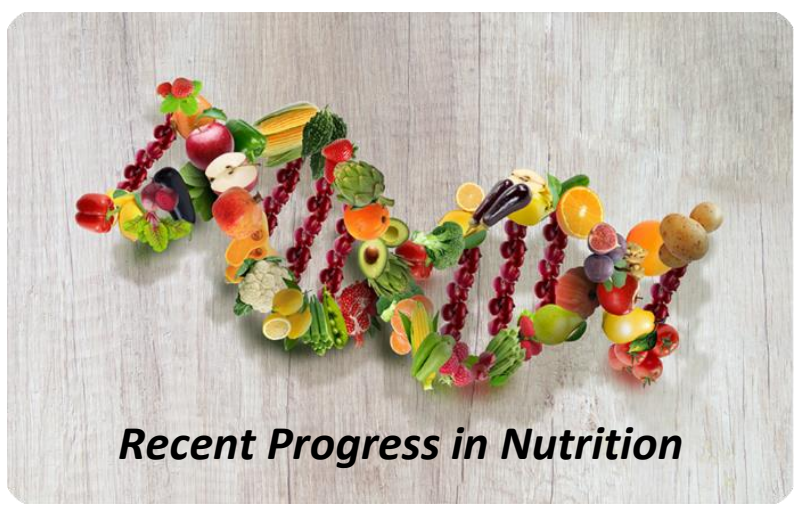

Enjoy Recent Progress in Nutrition by:

1. Submitting a manuscript

2. Joining in volunteer reviewer bank

3. Joining Editorial Board

4. Guest editing a special issue

For more details, please visit: http://www.lidsen.com/journals/rpn 